\title{
Dynamic Waste Management (DWM): A new step towards industrial ecology
}

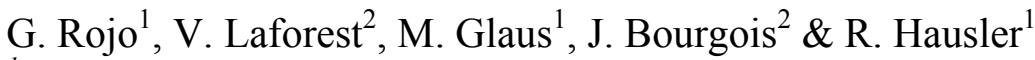 \\ ${ }^{1}$ Station Expérimentale des Procédés Pilotes en Environnement \\ (STEPPE), Ecole de Technologie Supérieure, Canada \\ ${ }^{2}$ Sciences, Information et Technologies pour l'Environnement (SITE), \\ Ecole Nationale Supérieure de Mines de Saint-Etienne, France
}

\begin{abstract}
The load caused by growing volumes of collected residues produces a pressure both on the environment and on the population. Presently, wastes are no longer considered just simple residues, but also resources which can be reused or recovered. Various tools are now available to help compare the various options in waste management. These tools lead to a linear management of the systems. In addition, they generate a division of flow streams and do not allow an optimal use of the available materials. An industrial ecology perspective requires one to move towards a systemic approach.

Based on the law of conservation of energy, the Dynamic Waste Management approach (DWM) studies the behaviour of systems to insure a constant supply of favourable waste management options (WMO) and to reduce the global load within these systems. The flow distribution in a global system rests on the principle that the available volumes and the transportation influence the validity of the hierarchical organisation of WMO. Adhering to the philosophy of industrial ecology, the DWM offers a dynamic and evolutionary alternative to reduce the impacts generated by inadequate waste management. The present article exposes the characteristics of the proposed approach, and presents an example of its application in order to demonstrate the advantages of the DWM.

Keywords: industrial ecology, waste management, decision-making tool, flow analysis, model simulation, dynamic approach, integrated management, law of conservation of energy.
\end{abstract}




\section{Introduction}

Due to the social, economical and environmental impacts associated with the waste generated by the industries and the populations, the importance to adopt good practices for the management of these residual materials is recognised and uncontested [1]. In industrialised countries, increased awareness of the impacts associated with landfill leads to an increased quantity of recovered residues [2]. In spite of the existence of various waste treatment methods, a considerable fraction of recovered materials end up in landfills because of the lack of adequate WMO facilities to reuse, recover, eliminate or dispose these wastes. Insufficient investments in this domain are due to the incapacity to estimate future volumes, the inability to ensure constant and sufficient supplies for the WMO and the difficulties in determining where the facilities should be located [3].

In addition to the problems associated with the resources flows in the system, the prioritisation order of the WMO can sometimes lead to erroneous, even inadequate, decision-making [4]. Presently, numerous tools exist to assist the waste hierarchy assessment for the WMO in a system and to designate which options must be prioritised. Among these tools, the life cycle assessment (LCA) is the most recommended approach [5]. Although some of the available tools take into account impacts associated with transportation, they continue to perform in a stationary way and do not allow for evolutionary observations [6]. According to the principle which states that a larger supply area of a system leads to increased impacts associated with transportation, the consequences directly influence the validity of the established hierarchical organisation. Therefore, it is essential to study the elements of a system by considering their dynamic, even chaotic behaviour, rather than analysing inflexible and linear scenarios. The application of an integrated management approach, which respects the concepts of industrial ecology, must also take into account intrinsic parameters associated with the flow movements within the network [7]. Besides the impacts associated with the choice of transportation and with the distance traveled, the route selected has a significant influence on prioritising one WMO rather than another due to the different impacts each route can generate [5].

The aim of waste management systems is to achieve global equilibrium by taking into account impacts related to transportation and to ensure an adequate supply of available WMO facilities. Thus, this paper presents a new approach to achieve a dynamic waste management of flow distribution. This approach is based on typical network methods and on the law of conservation of energy, but more particularly on Bernoulli's theorem. To validate the proposed approach and demonstrate that the system's behaviour adhere to the framework of an industrial ecology, the approach is then applied to an example.

\section{General approach of DWM}

\subsection{Basics principles of DWM}

The behaviour of a waste management system can be compared to a water distribution network: quantities of waste are generated, stored, and then distributed to recycling, recovery, elimination and/or disposal facilities (WMO). 
Contrary to the current approach of hierarchical organization, a network approach allows to manage the distribution of flows in a dynamic way which avoids cutting completely the supply of certain WMO. Using such a concept allows the different facilities to compliment each other rather than substitute each other. Similar to a water distribution network, waste management must no longer rely on the linear classification of the WMO, but rather on the global behaviour (global load) of the system. Thus, the system aims towards a steady state, and then if a punctual event causes an unusual volume of waste that needs to be managed or if the network is no longer fed, this system can enter in a transient state which is able to handle these events while reducing the repercussions to the WMO.

Moreover, similar to hydraulic networks, the transportation operation of the materials influences the equilibrium of the network as well as the distribution of the volumes in the system. The longer the path, the more energy is consumed, the less profitable and less likely this route will be chosen due to its impacts. One of the advantages of the DWM is that it respects the law of conservation of energy by integrating the notion of linear load losses (head loss). Considering the aforementioned comparisons, by using the hydraulic equations and by applying a network approach, it will be demonstrated that it is possible to manage a waste system in a dynamic way while maintaining it in an equilibrium state.

\subsubsection{Bernoulli's theorem}

The equilibrium equation according to Bernoulli (1) allows comparing the hydraulic balance between two points in a channel or in a conduit. The same equation is also used to analyze flow distribution in the hydraulic networks.

$$
\frac{v_{1}^{2}}{2 \cdot g}+h_{1}+\frac{P_{1}}{\rho \cdot g}=\frac{v_{2}^{2}}{2 \cdot g}+h_{2}+\frac{P_{2}}{\rho \cdot g}+\Delta H
$$

In this energy conservation equation, $\boldsymbol{\rho}$ represents the fluid's density $\left(\mathrm{kg} / \mathrm{m}^{3}\right)$, $\boldsymbol{v}$ its speed $(\mathrm{m} / \mathrm{s}), \boldsymbol{g}$ the gravitational acceleration $\left(\mathrm{m} / \mathrm{s}^{2}\right), \boldsymbol{h}$ the elevation $(\mathrm{m}), \boldsymbol{P}$ the pressure $\left(\mathrm{N} / \mathrm{m}^{2}\right)$ and $\Delta \boldsymbol{H}$ the head loss (m). The speed (v) and the head loss $(\Delta \boldsymbol{H})$ in a conduit at full capacity can also be presented as follows:

$$
\begin{gathered}
v=\frac{Q}{S}=\frac{4 \cdot Q}{\pi \cdot D^{2}} \\
\Delta H=\gamma \cdot \frac{L}{D} \cdot \frac{v^{2}}{2 \cdot g}=8 \gamma \cdot \frac{L}{D^{5}} \cdot \frac{Q^{2}}{g \cdot \pi^{2}}
\end{gathered}
$$

Where the parameters $\gamma, \boldsymbol{Q}, \boldsymbol{S}, \boldsymbol{D}$ and $\boldsymbol{L}$ represent the head loss coefficient (without unit), the flow $\left(\mathrm{m}^{3} / \mathrm{s}\right)$, the section $\left(\mathrm{m}^{2}\right)$, the diameter $(\mathrm{m})$ and the length (m) respectively. 


\subsubsection{The approach premises}

By considering the water system as being closed, filled to capacity and not affected by additional pressure, the load in the system can therefore be expressed with the potential energy. Furthermore, knowing that the incompressibility of a fluid keeps the speed equal at the entrance and at the exit of a conduit, it is possible to make the hypothesis that the system evolves without the influence of the kinetic energy or the pressure energy. Therefore equation (1) can be reduced to:

$$
h_{1}=h_{2}+\left(8 \gamma \cdot \frac{L}{D^{5}} \cdot \frac{Q^{2}}{g \cdot \pi^{2}}\right)
$$

Equation (4) represents the general formula to determine the hydraulic characteristics in a circular conduit according to the linear load losses. Based on this equation and on the correlations presented in Table 1, the generic formula of the DWM is represented by equation (6).

Table 1: Analogy: water network vs. waste management.

\begin{tabular}{|l|l|}
\hline WATER DISTRIBUTION NETWORK & WASTE MANAGEMENT SYSTEM \\
\hline Water treatment plant (source) & Source of generated waste \\
\hline Water distribution network (pipes) & Transport network (route, train, etc.) \\
\hline Reservoir & Storage of materials (reserve) \\
\hline Water demands (uses) & Supply of the WMO facilities \\
\hline
\end{tabular}

\subsection{The mathematical model of DWM}

In a closed water network where there is no pressure applied, flows are directed towards the lowest levels and they undergo a load loss based on the flow rate and the conduit characteristics (length, diameter, friction).

Knowing that the WMO in a waste management system have their own characteristics and that the transportation exhorts an additional impact, the application of the hydraulic concepts is an interesting choice. Thus, it becomes possible to study multi-option system's behaviour using a network approach.

\subsubsection{Loads in the system}

Presently, the recommended approach for waste management consists in organizing the different options into a hierarchy to support decision-making in a defined system. This classification involves comparing the available options according to one or several chosen variables. To achieve a dynamic management, the values obtained for the classification of the WMO must rather be used and converted to serve as the load of these options. This load is attributed to the WMO and is referred to the allocation index $(\boldsymbol{A I})$ associated with the final elevation $\boldsymbol{h}_{2}$ in the energy conservation equation. Using the DWM, the facilities are no longer fed one after the others, but rather simultaneously according to their load compared to the others. This approach has the advantage 
that it insures equilibrium in the system, it adapts itself more quickly to the fluctuations and it allows a better analysis of the impact of the use of an option on the whole network.

In addition to the load attributed to WMO, it is possible that the sources of the waste generated can also be prioritized in the system. To prioritize the waste generators (industries, cities, etc.), a load can be applied. This load, called the prioritization index $(\boldsymbol{P I})$, executes the same function as the elevation $\boldsymbol{h}_{\boldsymbol{1}}$ in the equations (1) and (4).

\subsubsection{Load losses associated to transports}

The transportation of wastes towards the WMO or towards the reserves also generates impacts which must be considered in the decision-making process. The longer the transportation path, the more energy is consumed; the more restrictive the path is, the greater the impact associated with the transportation causes an effect on the whole system. Thus, the more the influence of the transportation is important, the less a WMO will be prioritized. Using equation (3) to calculate the impacts related to the movements in the network, the load loss $\Delta \boldsymbol{H}$ becomes in the DWM an index loss associated with transportation $\left(\Delta \boldsymbol{I}_{T}\right)$ which influences the $\boldsymbol{A I}$ and can be formulated by:

$$
\Delta I_{T}=\alpha \cdot \frac{L}{R^{\beta}} \cdot Q^{\delta}
$$

In equation (5), the parameters $\boldsymbol{L}, \boldsymbol{R}$ and $\boldsymbol{Q}$ correspond to the length, the type of road and the amount of transportation made (flow rate) respectively. The variables $\boldsymbol{\alpha}, \boldsymbol{\beta}$ and $\boldsymbol{\delta}$, represent the coefficients associated with the parameters $\boldsymbol{L}$, $\boldsymbol{R}$ and $\boldsymbol{Q}$ attributed to the load losses (index losses) related to transportations. The value of these variables is influenced by the units used in the equation. These variables replace those associated with the hydraulic characteristics (equation 4) in order to adjust the parameter's value in the equation according to the characteristics of the system in question.

\subsubsection{Presentation of the general equation}

The application of the DWM approach requires an initial value assignment to the variables in the equation. This task consists in determining the influences of the transportation as compared to the impacts associated to the WMO. For example, it is possible to determine by the LCA the impacts associated with recycling, recovery, elimination or disposal of a waste, as well as the impacts associated with its transportation. It then becomes a matter of determining the influences associated with the transportation volumes, the type of vehicles employed and the path chosen. By replacing the parameters of the DWM approach in the equation of conservation of energy according to Bernoulli (4), the general equation which balances the network becomes: 


$$
I P=I A+\Delta I_{T}=I A+\left(\alpha \cdot \frac{L}{R^{\beta}} \cdot Q^{\delta}\right)
$$

Parallel to Bernoulli's theorem, equation (6) allows to measure the network's equilibrium state and to distribute the flows towards the WMO considered the most appropriate when several waste generators evolve in the same system and when various options are available. One of the advantages of this approach is that it is also possible to incorporate reserves and to study their influences on the system's behaviour.

\section{Example of application of the DWM approach}

The following example analyses the behaviour of a system composed by 3 waste generators, a reserve and by 3 waste management options (WMO). Due to the numerous mathematical constraints, the computing tool EPANET was used [8]. This tool simulates the water distribution systems using the Hazen-William equations, which are derived from the theorem of Bernoulli.

\subsection{Presentation of the studied network}

The studied network corresponds to a management system (wood wastes) evolving in a fixed area. Figure 1 presents the geographical localisation of the network in question as well as the main characteristics associated with the roads.
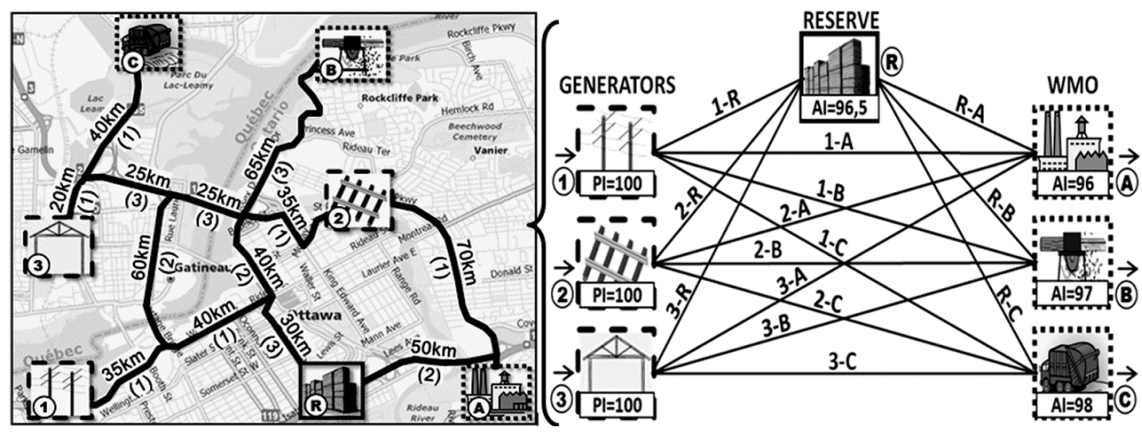

Figure 1: Map of the studied network and global diagram modeled in EPANET.

The system (Figure 1) contains 3 generators which produces wastes from: 1poles; 2- sleepers; 3 - beams. When they are introduced into the network, these wastes can go towards:
a. $\mathrm{R}$ - a reserve
(max. capacity: 10000 metric tons);
b. A - incineration
(max. capacity: 35 shipments per month);
c. B - recycling
(max. capacity: 45 shipments per month);
d. C - landfill
(max. capacity: 100000 metric tons). 
The distances presented on the map correspond to the lengths of each path and the numbers in parenthesis represent the type of road. In this example, 3 types of roads were considered: 1- highways; 2- boulevards and 3- streets. To facilitate the convergence during the simulation, flows are considered unidirectional and the network does not allow looping. Thus, transportations must be considered in an independent way and they can take various paths, but cannot go backward or pass through the same road twice. The representation of the management system model is made by positioning the actors on the network as nodes, then by using unidirectional paths as the transportation links between the nodes.

\subsection{Characteristics of the studied network}

For the purposes of the simulation, loads are converted into hydraulic pressures (metres) in the program EPANET. The prioritization indexes $(\boldsymbol{P I})$ and the attribution indexes $(\boldsymbol{A I})$ which served to balance the network appear in Figure 1. The time scale used during this simulation is fixed at ten months with time steps of one month. The selected flow's unit is equivalent to one transfer made by a truck or by a train, and can contain 20 metric tons per shipment. In this example, the flow fixed at one shipment per month replaces the usual unit of a cubic meter per second normally used in EPANET.

In this example, the generator's load $(\boldsymbol{P I})$ remains constant because no entering flows are prioritized within the network. In regards to the reserve, its capacity is fixed at 10000 metric tons (500 shipments) and it contains the equivalent of 125 shipments at the beginning of the simulation. The reservoir serves as a buffer zone; constraints are applied to avoid that it completely empties or that it becomes permanently full. Therefore, the more the level of the reserve is low, the more easily it can be supplied. On the other hand, the more the reserve is full, the more it exercises a pressure within the network to prioritize its evacuation. Using equation (5), the values used for $\boldsymbol{\beta}$ and $\boldsymbol{\delta}$ are 4.87 and 1.852 respectively and correspond to the default values fixed in EPANET. The same equation is then used to determinate the reference values of the load losses associated to the transportations. Table 2 presents the source data used during the simulation as well as the reference values calculated for $\boldsymbol{\alpha}$ which is a

Table 2: $\quad$ Load losses associated to transportation.

\begin{tabular}{|c|c|c|c|c|c|c|}
\hline Load loss & Road type & $\begin{array}{c}\text { Reference } \\
\text { length }\end{array}$ & $\begin{array}{c}\text { Reference } \\
\text { flow rate }\end{array}$ & $\begin{array}{c}\text { Transportation } \\
\text { mode }\end{array}$ & $\boldsymbol{\alpha}$ & $\mathbf{R}$ \\
\hline 0,50 & Highway & $100 \mathrm{~km}$ & 100 shipments/month & Train & $9,89 \mathrm{E}-10$ & 1 \\
\hline 0,55 & Highway & $100 \mathrm{~km}$ & 100 shipments $/$ month & Truck & $1,09 \mathrm{E}-09$ & 1 \\
\hline 0,55 & Boulevard & $100 \mathrm{~km}$ & 100 shipments $/$ month & Train & $9,89 \mathrm{E}-10$ & 0,9806 \\
\hline 0,60 & Street & $100 \mathrm{~km}$ & 100 shipments/month & Train & $9,89 \mathrm{E}-10$ & 0,9633 \\
\hline
\end{tabular}


Table 3: Characteristics related to transportation.

\begin{tabular}{|c|c|c|c|c|c||c|c|c|c|c|c|}
\hline Path & $\mathbf{L}$ & $\begin{array}{c}\text { Road type } \\
\text { (average) }\end{array}$ & $\mathbf{R}$ & $\begin{array}{c}\text { Transport } \\
\text { mode }\end{array}$ & $\boldsymbol{\alpha}$ & Path & $\mathbf{L}$ & $\begin{array}{c}\text { Road type } \\
\text { (average) }\end{array}$ & $\mathbf{R}$ & $\begin{array}{c}\text { Transport } \\
\text { mode }\end{array}$ & $\boldsymbol{\alpha}$ \\
\hline $1-\mathrm{R}$ & $105 \mathrm{~km}$ & 1,57 & 0,989 & Truck & $1,09 \mathrm{E}-09$ \\
\hline $1-\mathrm{A}$ & $180 \mathrm{~km}$ & 1,94 & 0,982 & Truck & $1,09 \mathrm{E}-09$ & $3-\mathbf{R}$ & $140 \mathrm{~km}$ & 2,43 & 0,973 & Truck & $1,09 \mathrm{E}-09$ \\
\hline $1-\mathrm{B}$ & $160 \mathrm{~km}$ & 1,69 & 0,986 & Truck & $1,09 \mathrm{E}-09$ & $3-\mathrm{B}$ & $60 \mathrm{~km}$ & 1,00 & 1,000 & Truck & $1,09 \mathrm{E}-09$ \\
\hline $1-\mathrm{C}$ & $155 \mathrm{~km}$ & 1,71 & 0,986 & Truck & $1,09 \mathrm{E}-09$ & $3-\mathrm{C}$ & $175 \mathrm{~km}$ & 1,57 & 0,989 & Truck & $1,09 \mathrm{E}-09$ \\
\hline $2-\mathrm{R}$ & $105 \mathrm{~km}$ & 1,95 & 0,981 & Truck & $1,09 \mathrm{E}-09$ & R-A & $135 \mathrm{~km}$ & 2,70 & 0,968 & Train & $9,89 \mathrm{E}-10$ \\
\hline $2-\mathrm{A}$ & $100 \mathrm{~km}$ & 2,30 & 0,975 & Truck & $1,09 \mathrm{E}-09$ & R-B & $160 \mathrm{~km}$ & 2,25 & 0,976 & Train & $9,89 \mathrm{E}-10$ \\
\hline $2-\mathrm{B}$ & $125 \mathrm{~km}$ & 1,80 & 0,984 & Truck & $1,09 \mathrm{E}-09$ & R-C & $50 \mathrm{~km}$ & 2,00 & 0,981 & Train & $9,89 \mathrm{E}-10$ \\
\hline 2-C & $70 \mathrm{~km}$ & 1,00 & 1,000 & Truck & $1,09 \mathrm{E}-09$ \\
\hline
\end{tabular}

function of the type of transportation, and for $\boldsymbol{R}$ which is function of the type of road used.

These load losses (Table 2) are the reference values which permitted to obtain $\boldsymbol{R}$ values (Table 3 ) according to the specific paths shown in Figure 1 .

\subsection{Results and discussion}

The results obtained during the simulation (Figure 2) demonstrates that the law of conservation of energy, according to Bernoulli's theorem, allows the distribution of the waste within the system to feed the most favorable WMO, to optimize the use of the reserves and to minimize the networks global load. The results illustrate that in spite of the fluctuations in the waste generated, the distribution was carried out while maintaining the network in a state of

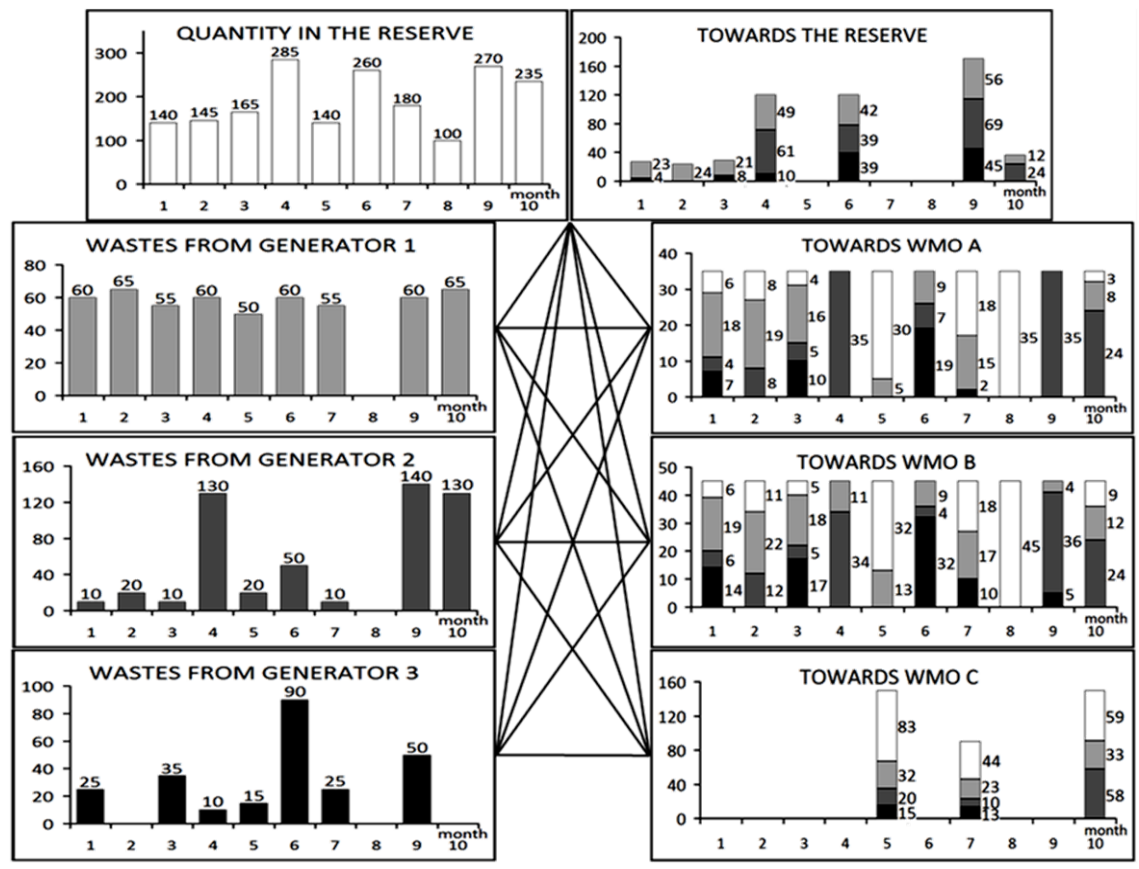

Figure 2: $\quad$ Network's flow distribution (shipments/month). 
equilibrium, in a minimal global load and while preserving an adequate volume in the reserve. In this example, the WMO $\boldsymbol{A}$ and $\boldsymbol{B}$ are continuously fed because their load $(\boldsymbol{I} \boldsymbol{A})$ is inferior to the reserve's state of equilibrium, and the WMO $\boldsymbol{C}$ receives a minimum flow due to its higher load. The results obtained show that, under certain conditions, it becomes more profitable to send the waste towards the less favorable WMO to insure the system's equilibrium and to reduce the global load.

With the DWM it becomes also possible to determine (1) the necessity to modify the capacity of the installations (WMO or reserves), (2) if some installations are useless or (3) if new ones are required. Moreover, if new installations are necessary it is possible to optimize their geographical location to minimize their load in the network.

Although EPANET enables to study the behavior of a waste management network, the equations are fixed and require a conversion for each of the variables. Furthermore, as the studied network's behavior is strongly influenced by the weight of the attributed indexes $\left(\boldsymbol{P I}, \boldsymbol{A I}\right.$ and $\left.\Delta \boldsymbol{I}_{T}\right)$, it is important to carefully determine these values. Consequently, it is necessary to develop new and better adapted tools to enable a more intuitive use.

The results clearly demonstrate that waste management based on the law of the conservation of energy provides a promising option which is able to support diversified ecologisation of industries. Furthermore, in waste management systems which aim to respect the ideas of sustainable development, it is essential to consider the distances traveled, the energy consumed by the means of transportation and the constraints caused by the type of road chosen. The DWM approach is capable of respecting these criteria by offering the administrators the possibility to study the behavior of a system in a flexible and dynamic way.

\section{Conclusion}

The results obtained during this simulation demonstrate that this unique dynamic waste management approach is an integrated approach which offers new perspectives in order to achieve responsible and durable industrial ecology. In comparison to the hydraulic networks where the system's flow distribution is influenced by the load loss in the conduits, the supply of WMO in a waste management network is carried out in an evolutive manner which must consider the transportation impacts. Thus, the law of the conservation of energy, according to Bernoulli's theorem, can be integrated into a network approach in order to correct the deficiencies found in the traditional linear approach of the waste management hierarchical organization.

With the growing volumes of collected residues occurring in industrialized countries, it becomes essential to reduce the environmental, economical and social pressure attributed to their elimination. To achieve this goal, the dynamic waste management approach remains an innovative, simple, flexible and evolutive alternative which allows its users to insure a constant supply to the favorable WMO, while minimizing the elimination towards the WMO which increase the global load of the system. 


\section{References}

[1] Kijak, R., Moy, D., A decision support framework for sustainable waste management, Journal of Industrial Ecology, 8(3), pp. 33-50, 2004.

[2] Bruvoll, A., Ibenholt, K., Future waste generation forecasts on the basis of a macroeconomic model, Resources, Conservation and Recycling, 19(2), pp. 137-149, 1997.

[3] Lang, D. J., Binder, C. R., Stauffacher, M., Ziegler, C., Schleiss, K., Scholz, R. W., Material and money flows as a means for industry analysis of recycling schemes: A case study of regional bio-waste management, Resources, Conservation and Recycling, 49(2), pp. 159-190, 2006.

[4] Kirkeby, J. T., Birgisdottir, H., Hansen, T. L., Christensen, T. H., Bhander, G. S. Hauschild, M., Environmental assessment of solid waste systems and technologies: EASEWASTE. Waste Management \& Research, 24(1), pp. 3-15, 2006.

[5] Ekvall, T., Assefa, G., Bjorklund, A., Eriksson, O., Finnveden, G., What life-cycle assessment does and does not do in assessments of waste management, Waste Management, 27(8), pp. 989-996, 2007.

[6] Bovea, M. D., Powell, J. C., Gallardo, A., Capuz-Rizo, S. F., The role played by environmental factors in the integration of a transfer station in a municipal solid waste management system, Waste Management, 27(4), pp. 545-553, 2007.

[7] Smith, R. L., Hierarchical design and evaluation of processes to generate waste-recycled feeds, Industrial and Engineering Chemistry Research, 43(10), pp. 2508-2515, 2004.

[8] Software that models the hydraulic and water quality behaviour of water distribution piping systems; U.S. Environmental Protection Agency, Water Supply and Water Resources Division Web Site, www.epa.gov/nrmrl/ wswrd/epanet.html 